\title{
Early Behavioral Experience and Adult Social Behavior in the Paradise Fish, Macropodus opercularis L.
}

\author{
JEFFREY KASSEL and ROGER E. DAVIS \\ Mental Health Research Institute, and the \\ Neuroscience Laboratory, University of Michigan \\ Ann Arbor, Michigan 48104
}

\begin{abstract}
Macropodus opercularis were reared in isolation, with conspecifics, or cross-reared with nonconspecifics. As young adults, cross-reared subjects presented with live conspecific and mirror image stimuli performed social displays less frequently than controls, while isolates did not differ from controls. In a spawning trial, no differences were found between groups. These results suggest that experience with an alien species may reduce the readiness to perform species-specific social displays.
\end{abstract}

Investigations of imprinting and attachment behavior indicate that social stimulation is necessary for the ontogeny of species-typical social behavior in mammals (Cairns, 1972) and in birds (Bateson, 1966, 1971). Juvenile mice, sheep, and dogs which have previously been kept with members of an alien species may show attachment behavior toward the nonconspecific (Denenberg, Hudgens, and Zarrow, 1964; Nagy, 1965; Cairns and Johnson, 1965; Cairns and Werboff, 1967; Fox, 1969). The effect of cross-species rearing on adults social behavior has apparently not been extensively investigated. As adults, Mus reared with Baiomys show a social preference for Baimoys, though the Mus freely mate with conspecifics (Quadagno and Banks, 1970). Lagerspetz and Heino (1970) found that mice cross-reared with rats preferred rats in a social preference test as adults, and showed reduced sexual behavior toward mice. Adult male guinea pigs which are reared with chickens or rats court conspecifics and the cross-reared species as well (Beauchamp and Hess, 1971, 1973). Social isolation beginning early in development has marked effects on adult behavior. Rats isolated as early as 14 days show normal sexual behavior (Beach, 1958), although neonatal isolation disrupts adult mating behavior (Gruendel and Arnold, 1969). Isolated male guinea pigs, cats, and dogs exhibit poorly organized sexual behavior patterns (Valenstein, Riss, and Young, 1955; Rosenblatt, 1965; Beach, 1968; Coulon, 1971) and isolation-reared rhesus monkeys show profound disruption of adult social behavior (Harlow and Harlow, 1966). In some birds the development of a juvenile social attachment 
influences adult sexual behavior. Male ducks, geese, turkeys, and zebra finches selectively court females of the imprinted species (Lorenz, 1937; Schein, 1963; Immelman, 1969). Sex differences in avian sexual imprinting could be related to external sexual dimorphism (Schutz, 1965).

There have been few investigations of early social experience and the ontogeny of species-typical behavior in fishes. The available results indicate that specific social interactions are not necessary for development. Lifelong social isolation does not block the development of sexual behavior in male platyfish, Xiphophorus maculatus (Shaw, 1962). Briefer reports on experiments in Gasterosteus aculeatus (Tinbergen, 1953), Hemichromis bimaculatus (Noble and Curtis, 1935/36), and Betta splendens and Macropodus sp. (Braddock and Braddock, 1958; Kuo, 1960) also indicate that social behavior develops in individuals which are isolated from the time of hatching. The aim of our experiment in paradise fish, Macropodus opercularis, was to determine whether rearing with nonconspecifics and rearing in total social isolation disrupts sexual behavior and the performance of specific social displays. Newly hatched fish were reared to adulthood in social isolation, with conspecifics or with blue gouramis (Trichogaster trichopterus). ${ }^{1}$ The readiness to perform social displays to live conspecifics and to mirror image stimuli was determined. Subsequently, the subjects were paired with group-reared conspecifics in reproductive behavior trials.

\section{METHODS}

Subjects

Forty-seven $M$. opercularis, bred from laboratory stock and raised in the laboratory, were used. Subjects were selected from two unrelated broods.

\section{Apparatus}

Rearing tanks were 2-liter $(13 \times 18 \times 9 \mathrm{~cm}$ high) plastic tanks, and 9.5 -liter $(30 \times 15 \times 20 \mathrm{~cm}), \quad 19$-liter $(35 \times 21 \times 25 \mathrm{~cm}), \quad$ and 38 -liter $(60 \times 22 \times 30 \mathrm{~cm})$ glass aquaria. Three sides of the rearing tanks were covered with white paper to block the subject's view of fish in other tanks. Water temperature was kept at $24-25^{\circ} \mathrm{C}$, and a $14: 10 \mathrm{hr}$ light:dark cycle was maintained.

The live-stimulus trial tank was a 9.5 liters $(30 \times 15 \times 20 \mathrm{~cm})$ glass aquarium arranged so that a $15-\mathrm{cm}$ wall faced the observer. An identical tank,

$1_{M}$. opercularis, subfamily, Macropodinae, and T. trichopterus, subfamily, Trichogasterinae, are in family Belontiidae, suborder Anabantoidei of the order Percomorphi. 
containing a live conspecific, was placed along the $30-\mathrm{cm}$ wall, and was shielded from the subject by a removable cardboard partition. To measure swimming activity, a vertical line was drawn at the middle of the $30-\mathrm{cm}$ wall.

The mirror stimulus trial tank was $40 \times 15 \times 20 \mathrm{~cm}$ high. The $40-\mathrm{cm}$ walls were clear glass; the $15-\mathrm{cm}$ walls and the bottom were nonreflecting black Plexiglas (Fig. 1). The tank was filled to $16 \mathrm{~cm}$ with fresh, dechlorinated $25^{\circ} \mathrm{C}$ water, which was changed between trials. Two $10 \times 20 \mathrm{~cm}$ high, black Plexiglas partitions marked the boundaries of the approach zones. On one of the partitions a $10 \times 16 \mathrm{~cm}$ mirror was fixed so that the fish could see its own image only when in the approach zone. To measure swimming activity a grid, consisting of three vertical lines dividing the tank into four $10-\mathrm{cm}$ wide columns and one horizontal line midway between the water surface and the tank bottom, was drawn on the $40-\mathrm{cm}$ glass walls.

Behavioral units were registered with a manual keyboard in conjunction with an Esterline Angus event recorder.

\section{Procedure}

Following spawning, embryos were collected and kept in small plastic dishes. On day 2 posthatching, subjects were assigned to one of three rearing conditions: Isolated subjects were placed singly in 2-liter tanks, and were transferred to 9.5-liter tanks at approximately 40 days. Cross-reared subjects were placed in 2-liter tanks with five newly hatched $T$. trichopterus. At days 30 and 50, the group was transferred to 9.5- and 18-liter aquaria. Occasionally, the $T$. trichopterus grew much larger than and dominated the $M$. opercularis subject, and were removed. Throughout rearing, cross-reared $M$. opercularis shared a tank with at least two, and usually four or five $T$. trichopterus. Controls were raised in conspecific groups of 15-20 individuals in 38-liter aquaria. The developing young were fed brine shrimp nauplii, supplemented by Tetramin Staple Food. Fish older than 40 days also received frozen adult brine shrimp.
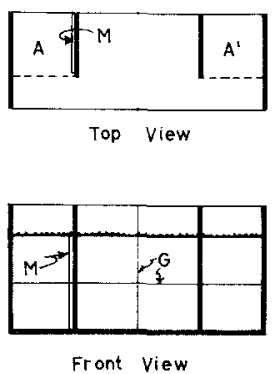

Fig. 1. Mirror trial tank. $M$, a $10 \times 16 \mathrm{~cm}$ mirror. $A$ and $\mathrm{A}^{\prime}$, the approach and approach' areas. G, lines of the activity grid on the front and rear walls. 


\section{Live Stimulus Trial}

A $10-$ min trial with a live stimulus was administered at 95 - to 100 days. Subjects were placed in the test tank $24 \mathrm{hr}$ prior to the trial. The partition was then removed to reveal a live conspecific in the adjacent tank. The stimulus fish was similar in size to the subject; the sex of the stimulus fish was not determined. The following behavior patterns (Davis and Kassel, 1975) of the subject were recorded: Approach consisted of movement of the subject to within 1 in. of the wall nearest the stimulus tank. Lateral display was recorded as the full extension of the anal, dorsal, and caudal fins with the body broadside to the opponent. Frontal display was defined as the extension of the opercula as the subject faced the stimulus fish. Attack consisted of a quick butting or biting thrust against the glass. Activity was recorded when the subject crossed the vertical line with its head. Air gulp was recorded when the subject surfaced to breath. The trial was started when the subject first approached the stimulus fish. Following the trial the subject was weighed, measured, and returned to the rearing tank.

Mirror stimulus trial. Ten days following the live stimulus trial the subject was isolated for $24 \mathrm{hr}$ in a 9.5-liter tank prior to the administration of a 10-min mirror trial. The trial was started when the subject first entered the approach zone (Fig. 1). The frequency and duration of approach, the frequency of lateral and frontal displays to the mirror image, and of air gulp were recorded. In addition, the frequency and duration of entries into the nonmirror zone, at the opposite end of the tank, were recorded as approach'. The preference for the mirror zone was determined by dividing the duration of approach by the sum of the durations of approach and approach'. A preference index of 0.5 thus signifies that equal time was spent in the two zones; an index of greater than 0.5 indicates a preference for the mirror zone. Activity was recorded as the frequency with which the fish crossed a vertical or horizontal line of the activity grid. Following the 10-min trial, the subject was returned to the rearing tank.

Mating test. At 120 days, four male and four female cross-reared subjects, and four male and six female isolate-reared subjects were placed in individual, heavily planted 38-liter aquaria with a control fish of the opposite sex. Eight pairs of controls were placed in similar tanks. The tanks were examined daily for the next 7 days for the presence of a nest containing eggs. Eggs were kept for 2 days to determine whether they had been fertilized.

\section{RESULTS}

The live stimulus trial results are summarized in Table 1. A KruskalWallis one-way analysis revealed significant treatment effect on lateral display $(H(2)=10.11, P<.007)$ and frontal display $(H(2)=6.28, P<.05)$ frequencies. Cross-reared subjects performed lateral and frontal displays less 
TABLE 1

Mean Frequency and Duration of Responses in the Live Stimulus Trial

\begin{tabular}{lccc}
\hline & $\begin{array}{c}\text { Cross-reared } \\
(n=15)\end{array}$ & $\begin{array}{c}\text { Isolated } \\
(n=16)\end{array}$ & $\begin{array}{c}\text { Control } \\
(n=16)\end{array}$ \\
\hline Lateral display & 0.2 & 3.4 & $3.9^{a}$ \\
Frontal display & 0.7 & 6.1 & $6.0^{b}$ \\
Approach frequency & 5.2 & 5.1 & 3.6 \\
Approach duration $(\mathrm{sec})$ & 487 & 516 & 435 \\
Attack & 10.3 & 12.0 & 6.2 \\
Activity & 54.0 & 24.8 & 55.2 \\
Air gulp & 11.0 & 7.4 & 8.1 \\
\hline
\end{tabular}

$$
\begin{aligned}
& { }^{a} P<.05 \\
& b_{P}<.01
\end{aligned}
$$

frequently than controls $(H(1)=9.87,5.81, P<.002, .02)$, and showed lateral display less frequently than the isolate-reared subjects $(H(1)=4.81$, $P<.03$ ). Controls and isolates did not differ in display frequency. No differences were seen in the other behavioral measures.

The mirror stimulus trial (Table 2), revealed significant treatment effects in lateral display $(H(2)=5.96, P<.05)$, frontal display $(H(2)=11.54$, $P<.003)$, and activity $(H(2)=13.60, P<.001)$ frequencies, and in no other measures. Cross-reared subjects showed lateral and frontal displays less frequently than the controls $(H(1)=3.88,10.74, P<.05, .002)$ and the isolates $(H(1)=4.76,6.41, P<.03, .02)$, while the controls and the isolates did not differ. The isolates were less active than control and cross-reared subjects

TABLE 2

Mean Frequency of Responses in the Mirror Stimulus Trial

\begin{tabular}{lccc}
\hline & $\begin{array}{c}\text { Cross-reared } \\
(n=15)\end{array}$ & $\begin{array}{c}\text { Isolated } \\
(n=14)\end{array}$ & $\begin{array}{c}\text { Control } \\
(n=15)\end{array}$ \\
\hline Lateral display & 3.3 & 10.4 & $9.3^{b}$ \\
Frontal display & 1.4 & 9.2 & $6.1^{c}$ \\
Activity & 105.8 & 57.1 & $89.7^{d}$ \\
Air gulp & 16.7 & 12.6 & $14.3^{d}$ \\
Approach & 2.2 & 2.8 & 2.1 \\
Preference index $^{a}$ & .76 & .81 & .64 \\
\hline
\end{tabular}

${ }^{a}$ Duration of approach/approach plus approach'.

$b_{P}<.05$.

$c_{P}<.003$.

$d_{P}<.001$. 
$(H(1)=8.81,10.43, P<.003, .002)$, while control and cross-reared groups did not differ.

No effects of the different rearing conditions were apparent in the mating trial. Five of the eight cross-reared subjects, two males and three females, eight of ten isolates, four males and four females, and six of the eight pairs of controls spawned within 1 week of pairing and produced viable offspring. Spawning latency was similar in the three groups.

In the live-stimulus trial, isolate-reared males showed a briefer approach duration than isolate-reared females $(H(1)=5.00, P<.03)$, while cross-reared males showed a longer approach duration than females $(H(1)=4.34, P<.04)$. Male cross-reared subjects showed air-gulp in the live stimulus trial less frequently than females $(H(1)=5.36, P<.03)$. There were no sex differences in the other behaviors in the live stimulus trial, and no sex differences in the mirror stimulus trial.

Growth rates showed a significant effect of rearing conditions (Table 3). Isolates were larger than control and cross-reared subjects (Scheffé $t$ test, $t=25.67,12.36, P<.001)$. Isolates were also heavier than control and crossreared fish $(t=27.51,9.80, P<.001, .004)$. Cross-reared subjects were heavier than the controls $(t=4.12, P<.05)$, but were not significantly greater in length.

\section{DISCUSSION}

This experiment indicates that the social behavior of $M$. opercularis can be modified by restricting experience with conspecifics during early development. Fish limited to contacts with nonconspecifics during development showed species-typical social displays much less frequently in brief encounters than did controls which were reared with conspecifics. The fact that the isolates were equivalent to the controls in display frequency indicates that in the cross-reared condition, it was not the absence of conspecifics which

TABLE 3

Biometric Data

\begin{tabular}{lccc}
\hline & Cross-reared & Isolated & Control \\
\hline Standard length $(\mathrm{mm})$ & 3.3 & 3.6 & 3.1 \\
Body weight (g) & 1.2 & 1.6 & 0.9 \\
Sex ratio (M:F) & $7: 8$ & $9: 7$ & $9: 7$ \\
\hline
\end{tabular}


interfered with development, but rather the presence of nonconspecifics. It may be noted that the differences between the groups cannot readily be attributed to mirror image stimulation from the glass walls of the rearing tanks during development, as mirroring, if any, was presumably similar in all tanks. Cross-species rearing and isolation did not impair mating success, suggesting that sexual imprinting does not occur in $M$. opercularis, but cross-species mating needs to be investigated.

One difficulty in interpreting the effects on social behavior of different rearing environments is the increase in emotionality and general hyperreactivity which can occur (Harlow and Harlow, 1966). The cross-reared fish did not appear to be more emotional than the controls. For example, the two groups showed similar frequencies of activity and air gulp. Isolates were less active than the controls and the cross-reared subjects in the mirror trial. They did not, however, freeze or otherwise appear hyperreactive. Furthermore, if the isolates were more emotional, it did not affect the frequencies of approach or display.

Males and females showed similar frequencies of display. A previous investigation showed that adult males perform lateral display at a higher rate than females (Davis, Harris, and Shelby, 1974). Adolescent males and females (days 70-100), however, showed equivalent low frequencies of lateral display (Davis and Kassel, 1975). This suggests that the present fish, at 95 to 105 days of age, were in the late adolescent stage. Such individuals show only weak sexual dimorphism. In the live stimulus trial, the sex of the opponent in the adjoining tank was not determined. The possible influence of sex differences in the opponent's behavior on the display rate of the adolescent, under these conditions, remains to be investigated.

These results suggest that the performance of social displays in $M$. opercularis is not learned, but that the readiness to display can be influenced by prior social environment. While the cross-reared subjects were not routinely observed during development, individuals were seen to chase and attack one another. These species, even as adults, rarely display to each other (Johnson and Peeke, 1972). Moreover, T. trichopterus does not perform a frontal or opercular spread display (Miller and Miller, 1970), and a T. trichopterus in lateral display bears little resemblance to $M$. opercularis; the color patterns, and the shape and extent of the spread fins are very different. The lack of reciprocal behaviors by $T$. trichopterus may have resulted in a decrease in the readiness of $\boldsymbol{M}$. opercularis to execute displays. However, the inhibition would seem to be reversible. Within a few minutes of pairing in the spawning test, cross-reared subjects performed displays at high rates, and their behavior was indistinguishable from controls. This confirms our impression that cross-rearing 
only raises the threshold of response. The inhibition of display does not necessarily represent a developmental effect. Prolonged exposure to an alien species in adulthood, with a concomitant absence of conspecifics, might similarly reduce the tendency to perform species-typical displays.

\section{REFERENCES}

Bateson, P. P. G. (1966). The characteristics and context of imprinting. Biol. Rev. 41, 177-220.

Beach, R. (1958). Normal sexual behavior in male rats isolated at fourteen days of age. $J$. Comp. Physiol. Psych. 51, 37-38.

Beach, F. (1968). Coital behavior in dogs: III. Effects of early isolation on mating behavior in males. Behaviour 30, 218-238.

Beauchamp, G. K., and Hess, E. H. (1971). The effects of ctoss-species rearing on the social and sexual preferences of guinea pigs. Z. Tierpsychol. 28, 69-76.

Beauchamp, G. K., and Hess, E. H. (1973). Abnormal early rearing and sexual responsiveness in male guinea pigs. J. Comp. Physiol. Psych. 85, 383-396.

Braddock, J. C., and Braddock, Z. I. (1958). Effects of isolation and social contact upon the development of aggressive behavior in the Siamese fighting fish, Betta splendens. Anim. Behav. 6, 249.

Cairns, R. B. (1972). Fighting and punishment from a developmental perspective. In J. K. Cole and D. D. Jensen (Eds.) "Nebraska Symposium on Motivation," Vol. 20, pp. 59-124. Lincoln: University of Nebraska Press.

Cairns, R. B., and Johnson, D. L. (1965). The development of interspecies social attachment. Psychon. Sci. 2, 337-338.

Cairns, R. B., and Werboff, J. (1967). Behavior development in the dog: an interspecific analysis. Science 158,1070 .

Coulon, J. (1971). Influence de l'isolement social sur le comportement du cobaye. Behaviour 38, 91-120.

Davis, R. E., Harris, C., and Shelby, J. (1974). Sex differences in aggresivity and the effects of social isolation in the anabantoid fish, Macropodus opercularis. Behav. Biol. 11, 497-509.

Davis, R. E., and Kassel, J. (1975). The ontogeny of agonistic behavior and the onset of sexual maturation in the paradise fish, Macropodus opercularis (Linnaeus). Behav. Biol. 14, 31-39.

Denenberg, V. H., Hudgens, G. A., and Zarrow, M. X. (1964). Mice reared with rats: modification of behavior by early experience with another species. Science 143, 380-381.

Fox, M. W. (1969). Behavioral effects of rearing dogs with cats during the "critical period of socialization." Behaviour 35, 273-280.

Gruendel, A. D., and Arnold, W. J. (1969). Effects of early social deprivation on reproductive behavior of male rats. J. Comp. Physiol. Psych. 67, 244-272.

Immelman, K. (1969). Uber den Einfluss frukikinlicher Erfahrungen auf die geschlectliche objektfixierung bei estrildiden. Z. Tierpsychol. 26, 677-691.

Johnson, H. G., and Peeke, H. V. S. (1972). Patterns of intra- and interspecific aggression in labyrinth fish (Belontiidae), Behav. Biol. 7, 335-348.

Kuo, Z. Y. (1960). Studies on the basic factors in animal fighting: V. Inter-species coexistence in fish. J. Genet. Psych. 97, 181-194. 
Lagerspetz, K., and Heino, T. (1970). Changes in social reactions resulting from early experience with another species. Psych. Rep. 27, 255-262.

Lorenz, K. (1937). The companion in the bird's world. $A u k$ 54, 245-273.

Miller, R. J., and Miller, H. C. (1970). Studies on the agonistic behavior of anabantoid fishes. Proc. Okla. Acad. Sci. 49, 60-85.

Nagy, Z. M. (1965). Effect of early environment upon later social preference in two species of mice. J. Comp. Physiol. Psych. 60, 98-101.

Noble, G. K., and Curtis, B. (1935/36). Sexual selection in fishes. Anat. Rec. 64, 84-85.

Quadagno, D. M., and Banks, E. M. (1970). The effects of reciprocal cross fostering on the behavior of rodents. Mus musculus and Baiomys taylori ater. Anim. Behav. 18, 379-390.

Rosenblatt, J, S. (1965). Effects of experience on sexual behavior in male cats. In F. Beach (Ed.), "Sex and Behavior." New York: Wiley.

Schein, M. W. (1963). On the irreversibility of imprinting. Z. Tierpsychol. 22, 50-103.

Shaw, E. (1962). Environmental conditions and the appearance of sexual behavior in the platyfish. In E. Bliss (Ed.), "Roots of Behavior." New York: Harper.

Tinbergen, N. (1953). "Social Behavior in Animals." London: Methuen.

Valenstein, E. S., Riss, W., and Young, W. C. (1955). Experimental and genetic factors in the organization of sexual behavior in male guinea pigs. J. Comp. Physiol. Psych. 48, 397-403. 